\title{
Edible colours and their scope
}

\author{
RAKESH KUMAR, SHIVANI SHARMA AND A.P.S. BRAR
}

Received: 25.04.2014; Accepted: 14.11.2014

See end of the paper for authors' affiliations

\section{RAKESH KUMAR}

Krishi Vigyan Kendra, FARIDKOT (PUNJAB) INDIA
ABSTRACT : In the present era of life, most of the peoples are busy in jobs and have very little time for preparation food for their family and hence, dependent upon the processed food products i.e. ready to serve meal. In such type of food products, the natural ingredients undergo processing which impact upon the appearance of the food. Moreover, the consumer goes for shopping on less frequent basis therefore the shelf-life of food products becomes a key consideration. To restore the originality of the food products, the manufacturers are using food colours. These colours can be artificial or natural. Many types of natural and artificial colours are being used by the manufactures to maintain the particular shade of a product for the duration of shelf-life. Despite, widespread use of colourants (synthetic) in food products, repots of allergic reaction, indigestion have been reported from additives. Very few report for turmeric, carmine, annatto and saffron were reported, though nobody gave conformity. Thus, it may be concluded that natural colours are safe and could be used into processed foods in place of synthetic ones to enhance the appeal of the processed food.

KEY WORDS: Food colour, Synthetic colour, Natural colour

- HOW TO CITE THIS PAPER : Kumar, Rakesh, Sharma, Shivani and Brar, A.P.S. (2014). Edible colours and their scope. Asian J. Home Sci., 9 (2) : 615-619. 